\title{
Influence of the microstructure on the cyclic stress-strain behaviour and fatigue life in hypo-eutectic Al-Si-Mg cast alloys
}

\author{
Jochen Tenkamp ${ }^{1, *}$, Alexander Koch ${ }^{1}$, Stephan Knorre ${ }^{2}$, Ulrich Krupp ${ }^{2}$, Wilhelm Michels ${ }^{2}$, and Frank Walther ${ }^{1}$ \\ ${ }^{1}$ TU Dortmund University, Department of Materials Test Engineering (WPT), D-44227 Dortmund, Germany \\ ${ }^{2}$ University of Applied Sciences Osnabrueck, Institute of Materials Design and Structural Integrity, D-49009 Osnabrueck, Germany
}

\begin{abstract}
Aluminium alloys are promising candidates for energy- and cost-efficient components in automotive and aerospace industries, due to their excellent strength-to-weight ratio and relatively low cost compared to titanium alloys. As modern cast processing and post-processing, e.g. hot isostatic pressing, result in decreased frequency and size of defects, the weakest link depends on microstructural characteristics, e.g. secondary dendrite arm spacing (SDAS), Si eutectic morphology and $\alpha$-Al solid solution hardness. Hereby, fatigue investigations of the effect of the microstructure characteristics on the cyclic stress-strain behaviour as well as fatigue mechanisms in the low cycle and high cycle fatigue regime are performed. For this purpose, samples of the aluminium cast alloy EN AC-AlSi7Mg0.3 with different $\mathrm{Si}$ eutectic morphology and $\alpha$-Al solid solution hardness were investigated. To compare the monotonic and cyclic stress-strain curves, quasistatic tensile tests and incremental step tests were performed on two microstructure conditions. The results show that the cyclic loading leads to a hardening of the material compared to monotonic loading. Based on damage parameter Woehler curves, it is possible to predict the damage progression and fatigue life for monotonic and cyclic loading in hypo-eutectic Al-Si-Mg cast alloys by one power law.
\end{abstract}

\section{Introduction}

Aluminium alloys are promising candidates for energyand cost-efficient components in automotive and aerospace industries, due to their excellent strength-to-weight ratio and relatively low cost compared to titanium alloys. Hereby, Al-Si alloys belong to the most common alloys in industry, as they achieve a market share of 70 to $80 \%$. As modern cast processing and post-processing, e.g. hot isostatic pressing, result in decreased frequency and size of defects (oxides, porosity) [1-5], the weakest link depends on microstructural characteristics, e.g. secondary dendrite arm spacing (SDAS) [6-8], Si eutectic morpho-logy [6, 9-12] and Al solid solution hardness. They are relevant to ensure a safe design for safety-relevant components made of aluminium cast alloys. While the impact of porosity and SDAS on S-N curve has already been investigated, the effect of microstructure characteris-tics as Si eutectic morphology and $\alpha$-Al solid solution hardness on the cyclic stressstrain behaviour as well as fatigue mechanisms in the low (LCF), high (HCF) and very high cycle fatigue (VHCF) regime is not well understood.

For this purpose, samples of the aluminium cast alloy EN AC-AlSi7Mg0.3 were casted in a steel mold with grain refinement and $\mathrm{Sr}$ modification. To avoid cast porosity, all samples were hot isostatically pressed
(HIP). To investigate the influence of $\mathrm{Si}$ eutectic morphology and Al solid solution hardness, T6 heat treatment was variated. To compare the monotonic and cyclic stress-strain curves, quasistatic tensile tests and incremental step tests (IST) were performed on two microstructure conditions, which vary in solution annealing temperature resulting in different $\mathrm{Si}$ eutectic morphologies and $\alpha$-Al solid solution hardness. Based on incremental step tests, cyclic stress-strain curves were determined. To validate the determined cyclic stress strain curves based on IST, strain- and stress-controlled fatigue tests at constant amplitude in the LCF and HCF regime from $10^{2}$ to $10^{7}$ cycles were performed. The fatigue progress was monitored by using correlated online hysteresis analysis and fractographic investigations. Finally, micro hardness mappings were carried out on longitudinal cross sections of fractured specimens to determine the effect of cyclic loading related to the specific $\mathrm{Si}$ eutectic morphology and the $\alpha$-Al solid solution hardness.

\section{Material and experimental setup}

\subsection{Material and microstructure}

*orresponding author: jochen.tenkamp@tu-dortmund.de 
For the characterisation of the effect of microstructural features on the fatigue behaviour, samples of the aluminium cast alloy EN AC-AlSi7Mg0.3 were casted in a steel mold with grain refinement $\left(\mathrm{AlTi}_{5} \mathrm{~B}_{1}\right)$ and $\mathrm{Sr}$ modification. The alloys were molten in an electric resistance furnace, including the alloying procedure. The melt was heated up to $730{ }^{\circ} \mathrm{C}$ and poured into a steel mold, which was pre-heated to $450{ }^{\circ} \mathrm{C}$. From the cast samples $(\varnothing 19 \mathrm{~mm} \times 185 \mathrm{~mm})$ the sprue and riser were cut off. To avoid the influence of cast porosity, all samples were hot isostatically pressed by Densal ${ }^{\mathrm{TM}}$. To investigate the influence of $\mathrm{Si}$ eutectic morphology and $\alpha-\mathrm{Al}$ solid solution hardness, the T6 heat treatment was variated in form of different solution annealing temperatures of (A) $530{ }^{\circ} \mathrm{C}$ and (B) $545{ }^{\circ} \mathrm{C}$ for one hour in an air-circulated furnace, quenched in water at room temperature and afterwards artificially aged at $160{ }^{\circ} \mathrm{C}$ for five hours. The two T6 heat treatment conditions are further called T6/A $\left(530^{\circ} \mathrm{C} / 1 \mathrm{hrs}\right)$ and $\mathrm{T} 6 / \mathrm{B}$ $\left(545^{\circ} \mathrm{C} / 1 \mathrm{hrs}\right)$. The chemical composition was analysed by means of spark emission spectroscopy and is shown in Table 1.

Table 1. Chemical composition of the aluminium cast alloy EN AC-AlSi7Mg0.3, all data in wt-\%.

\begin{tabular}{|c|c|c|c|c|c|}
\hline Si & Mg & Fe & Mn & Ti & Al \\
\hline 7.5 & 0.288 & 0.094 & 0.0018 & 0.146 & Bal. \\
\hline
\end{tabular}

Samples for basic characterisation were cold-embedded, ground and polished to a grit size of $0.3 \mu \mathrm{m}$ using oxide polishing suspension (colloidal $\mathrm{SiO}_{2}$ ). The grain size was determined in micrographs by means of Barker etching technique and quantified by linear intercept method (Fig. 1a) under polarised light using a stereoscopic light microscope. The secondary dendrite arm spacing (SDAS) and the formation of silicon particles were analysed on cross sections polished finally by oxide dispersion suspension (OPS) (Fig. 1b). Hereby, the SDAS was determined by linear intercept method based on a minimum of ten dendrites at $50 \times$ magnification. The grain size was determined to $620 \pm 330 \mu \mathrm{m}$ and the SDAS to $35 \pm 5 \mu \mathrm{m}$.
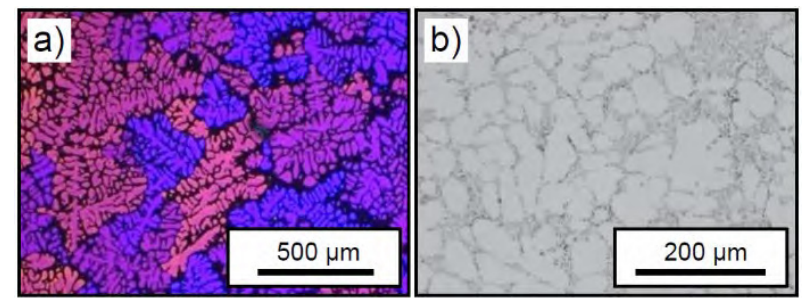

Fig. 1. Light micrographs: a) Barker etched (grains) and b) ODS polished (SDAS and Al-Si interdendritic eutectic).

To evaluate the characteristics of the Si particles within the interdendritic Al-Si eutectic, the image processing program ImageJ has been used to quantify size and shape by a binary greyscale analysis on micrographs with $500 \times$ magnification on a minimum of five micrographs.

The effects of casting and T6 heat treatment on the morphology of Si particles are illustrated in Fig. 2 by representative micrographs of as-cast material without T6 heat treatment (Fig. 2a), heat treatment T6/A (Fig. 2b) and T6/B (Fig. 2c). The morphology of $\mathrm{Si}$ particles was quantified by means of average value of area, perimeter, major and minor dimension as well as sphericity for the Si particles. The sphericity $\mathrm{S}$ was determined by following equation

$$
S=2\left(\pi \cdot A_{\text {real }}\right)^{0.5} / P_{\text {real }}
$$

using real area $\mathrm{A}_{\text {real }}$ and perimeter $\mathrm{P}_{\text {real }}$. The sphericity takes values between 0 and 1 , whereby 1 is attributed to an ideal spherical particle. For each batch, around 1,300 $\mathrm{Si}$ particles were analysed to determine representative values. In Table 2, the values of Si eutectic morphology are compared for botch batches.

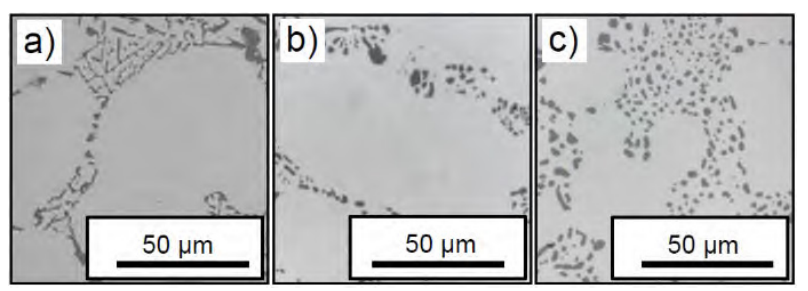

Fig. 2. Si particles within the Al-Si eutectic: a) as-cast without T6 heat treatment as well as after b) T6/A and c) T6/B heat treatment.

Table 2. Morphology characteristics of Si particles in interdendritic Al-Si eutectic for batches T6/A and T6/B

\begin{tabular}{|c|c|c|c|c|c|}
\hline \multirow{2}{*}{ Batch } & \multirow{2}{*}{$\begin{array}{c}\mathbf{A}_{\text {real }} \\
{\left[{\left.\mu \mathrm{m}^{2}\right]}^{2}\right]}\end{array}$} & \multirow{2}{*}{$\begin{array}{c}\mathbf{P}_{\text {real }} \\
{[\mu \mathrm{m}]}\end{array}$} & \multicolumn{2}{|c|}{ Dimension $[\mu \mathrm{m}]$} & \multirow{2}{*}{$\begin{array}{c}\mathbf{S} \\
{[-]} \\
\end{array}$} \\
\hline & & & Major & Minor & \\
\hline T6/A & 3.82 & 7.63 & 2.64 & 1.56 & 0.86 \\
\hline T6/B & 5.69 & 9.69 & 3.25 & 1.79 & 0.84 \\
\hline
\end{tabular}

The microstructure analyses show that the T6 heat treatment leads to a coarsening of Si particles at higher solution annealing temperatures. Botch batches show a high and comparable sphericity of Si particles due to the heat impact of HIP treatment and T6 heat treatment, respectively.

The effect of age hardening on the hardness of microstructure was measured by a micro hardness testing system using a force of $0.09807 \mathrm{~N}$ (HV0.1). The micro hardness was determined to $103 \pm 4 \mathrm{HV} 0.1$ and $110 \pm$ 4 HV0.1 for batch T6/A and T6/B, respectively. The increased hardness of $\alpha-\mathrm{Al}$ solid solution in batch $\mathrm{T} 6 / \mathrm{B}$ is attributed to the increased solubility of magnesium at solution temperatures of $545{ }^{\circ} \mathrm{C}$ compared to $530{ }^{\circ} \mathrm{C}$. Due to this, an increased age hardening of the $\alpha$-Al solid solution by the formation of $\mathrm{Mg}_{2} \mathrm{Si}$ precipitates can be realised. 


\subsection{Quasistatic testing}

To determine the monotonic stress-strain behaviour of batches $\mathrm{T} 6 / \mathrm{A}$ and $\mathrm{T} 6 / \mathrm{B}$, quasistatic tensile tests were performed using a universal testing machine (Instron 3369) with a load cell of $50 \mathrm{kN}$. The strain was determined by means of tactile extensometer with a gage length of $10 \mathrm{~mm}$. The test was performed straincontrolled at a strain rate of $0.07 \cdot 10^{-3} / \mathrm{s}$ in elastic region and $0.25 \cdot 10^{-3} / \mathrm{s}$ in elastic-plastic region of stress-strain curve related to DIN 6892-1. The specimen geometry used for both quasistatic and low cycle fatigue (LCF) tests is shown in Fig. 3a. The specimen geometry used for high cycle fatigue (HCF) tests is shown in Fig. 3b. The specimens were machined in accordance with DIN EN 6072:2011-06. Hereby, the gage sections were ground and polished up to $1 \mu \mathrm{m}$ diamond paste.

(a)

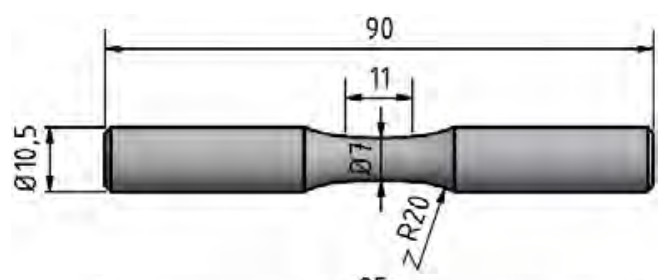

(b)

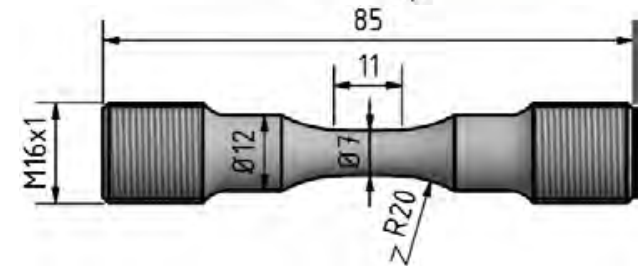

Fig. 3. Specimen geometries for (a) quasistatic and LCF testing as well as (b) HCF testing.

\subsection{Fatigue testing}

To characterise the fatigue behaviour in the low cycle fatigue (LCF) and high cycle fatigue (HCF) regime, tests were performed at servo-hydraulic as well as resonant testing systems, all at room temperature.

For LCF tests a servo-hydraulic testing system Schenck PC63M equipped with a load cell of $63 \mathrm{kN}$ at a frequency of $0.1 \mathrm{~Hz}$ was used. Hereby, the LCF tests were carried out total strain-controlled with a strain ratio of $\mathrm{R}_{\varepsilon}=-1$. Incremental step tests (IST) and constant amplitude tests (CAT) were performed to determine the LCF behaviour. Within the IST, the total strain amplitude $\varepsilon_{\mathrm{a}, \mathrm{t}}$ was increased each cycle by $\Delta \varepsilon_{\mathrm{a}, \mathrm{t}}=0.01 \%$, starting from $\varepsilon_{\mathrm{a}, \mathrm{t} \text { min }}=0.05 \%$ until reaching $\varepsilon_{\mathrm{a}, \mathrm{t} \text { max }}=$ $0.7 \%$, following a decrease of total strain amplitude by $\Delta \varepsilon_{a, t}$ until $\varepsilon_{a, t, m i n}$. These blocks of increasing and decreasing total strain amplitude were repeated until failure. CAT were carried out at a total strain amplitude of $\varepsilon_{\mathrm{a}, \mathrm{t}}=0.7 \%$.

HCF tests were conducted on resonant fatigue testing system Rumul Testronic equipped with a load cell of $20 \mathrm{kN}$ at a frequency of around $65 \mathrm{~Hz}$. The HCF behaviour was characterised in stress-controlled CAT with a load ratio of $\mathrm{R}=-1$ at various stress amplitudes $\sigma_{\mathrm{a}}$ between 100 and $260 \mathrm{MPa}$.

\section{Results and discussion}

\subsection{Monotonic stress-strain behaviour}

To determine the monotonic properties of batches T6/A and T6/B quasistatic tensile tests were performed. The determined stress-strain curves are plotted in Fig. 4. Batch T6/B shows an increased yield strength compared to T6/A, while both batches show comparable Young's modulus, tensile strength and fracture strain. The quasistatic properties are quantified in Table 3.

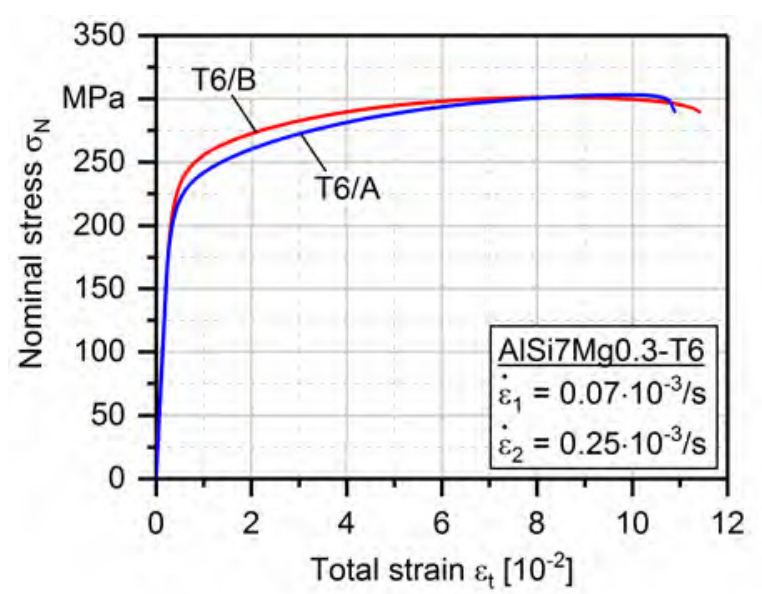

Fig. 4. Monotonic stress-strain curves for batches T6/A and $\mathrm{T} 6 / \mathrm{B}$ based on quasistatic tensile tests.

The differences in yield strength can be attributed to the increased age hardening of $\alpha$-Al solid solution in T6/B compared to $\mathrm{T} 6 / \mathrm{A}$ due to higher solution temperature during T6/B heat treatment, which could be determined by micro hardness measurements.

Table 3. Monotonic properties based on quasistatic tensile tests.

\begin{tabular}{|c|c|c|c|c|c|}
\hline Batch & $\begin{array}{c}\mathbf{E} \\
{[\mathbf{G P a}]}\end{array}$ & $\begin{array}{c}\boldsymbol{\sigma}_{\mathbf{y} 0.02} \\
{[\mathbf{M P a}]}\end{array}$ & $\begin{array}{c}\sigma_{\mathbf{y} 0.2} \\
{[\mathbf{M P a}]}\end{array}$ & $\begin{array}{c}\sigma_{\text {UTS }} \\
{[\mathbf{M P a}]}\end{array}$ & $\begin{array}{c}\boldsymbol{\varepsilon}_{\mathrm{t}} \\
{\left[\mathbf{1 0}^{-2}\right]}\end{array}$ \\
\hline $\mathbf{T 6} / \mathbf{A}$ & 72.5 & 183.7 & 220.6 & 303.2 & 10.9 \\
\hline $\mathbf{T 6} / \mathbf{B}$ & 72.8 & 187.4 & 233.4 & 301.3 & 11.4 \\
\hline
\end{tabular}

\subsection{Cyclic stress-strain behaviour}

The cyclic stress-strain behaviour was determined by incremental step tests (IST). The correlation between hysteresis curves in IST and the cyclic stress-strain behaviour or curve, respectively, is shown in Fig. 5 and detailed explained in [13]. 


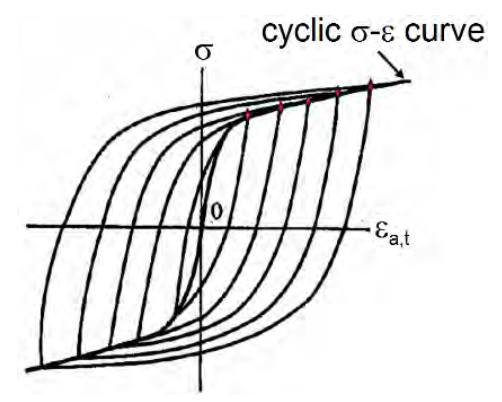

Fig. 5. Correlation of hysteresis curves of IST and the cyclic stress-strain curve [13].

The cyclic stress-strain curves are shown in Fig. 6 for batch T6/A and in Fig. 7 for batch T6/B. Hereby for each batch, the progression of cyclic stress-strain curve related to each block of IST is shown for three characteristic blocks $1^{\text {st }}, 2^{\text {nd }}$ and cyclic saturation $\left(4^{\text {th }}\right.$ for T6/A and T6/B) compared to last block before failure ( $7^{\text {th }}$ for $T 6 / A$ and $6^{\text {th }}$ for $\left.T 6 / B\right)$.

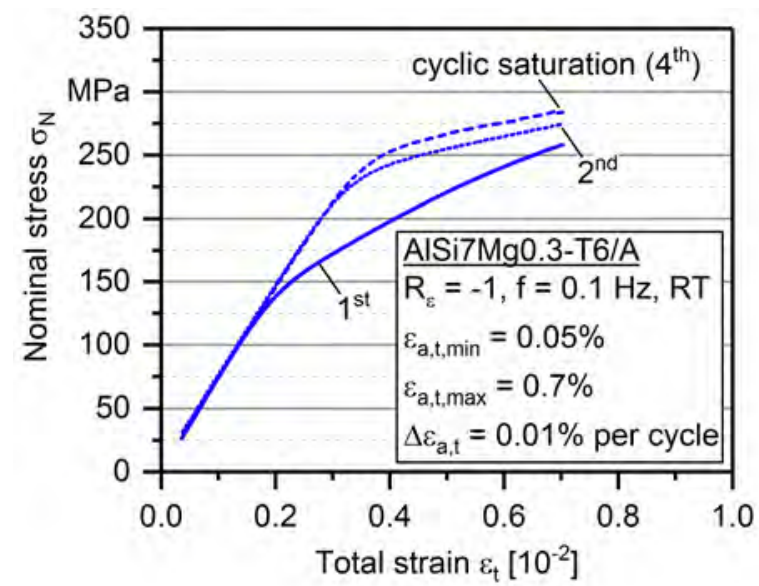

Fig. 6. Cyclic stress-strain curves for batch T6/A based on IST for three characteristic IST blocks $\left(1^{\text {st }}, 2^{\text {nd }}\right.$ and $\left.4^{\text {th }}\right)$.

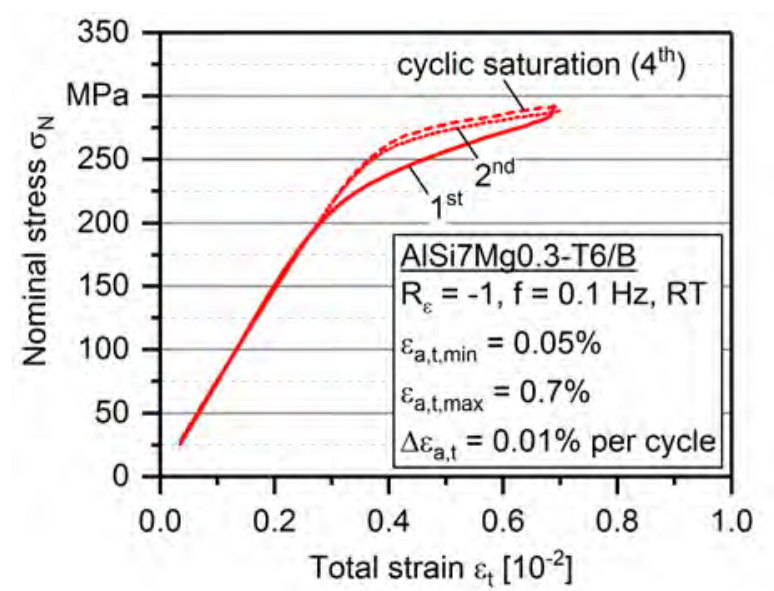

Fig. 7. Cyclic stress-strain curves for batch T6/B based on IST for three characteristic IST blocks $\left(1^{\text {st }}, 2^{\text {nd }}\right.$ and $\left.4^{\text {th }}\right)$.

For each batch, the material shows a significant cyclic hardening after $1^{\text {st }}$ IST block, whereby batch T6/A shows a significantly decreased cyclic yield strength in the first block compared to batch T6/B. A cyclic saturation of the stress-strain behaviour could be determined for botch batches. Hereby, batch T6/B shows a nearby cyclic saturation for the $2^{\text {nd }}$ block of IST, as no significant change could be determined compared to the cyclic saturated curve of $4^{\text {th }}$ block. For batch T6/A, a cyclic saturated stress-strain curve could be determined for $4^{\text {th }}$ block of IST.

In Fig. 8, the monotonic and cyclic stress-strain curves are compared for batches T6/A and T6/B. Related to IST, the last full block before failure $\left(6^{\text {th }}\right.$ for T $6 / \mathrm{A}$ and $4^{\text {th }}$ for $\mathrm{T} 6 / \mathrm{B})$ was used for the cyclic saturated stress-strain curve for each batch. Botch batches show a significant cyclic hardening of the material. Hereby, the tendency of an increased strength or yield strength, respectively, can be determined for batch T6/B for both monotonic and cyclic stress-strain behaviour. Additionally, the CAT are plotted in Fig. 7. The stress and total strain values were deter-mined for strain- and stress-controlled CAT at half number of cycles to crack initiation. The procedure to determine the fatigue crack initiation during fatigue testing will be explained in 3.3. The cyclic stress-strain curves determined by IST and CAT fit very well (Fig. 8). Related to [14], this indicates that the investigated aluminium alloys feature a planar slipping character.

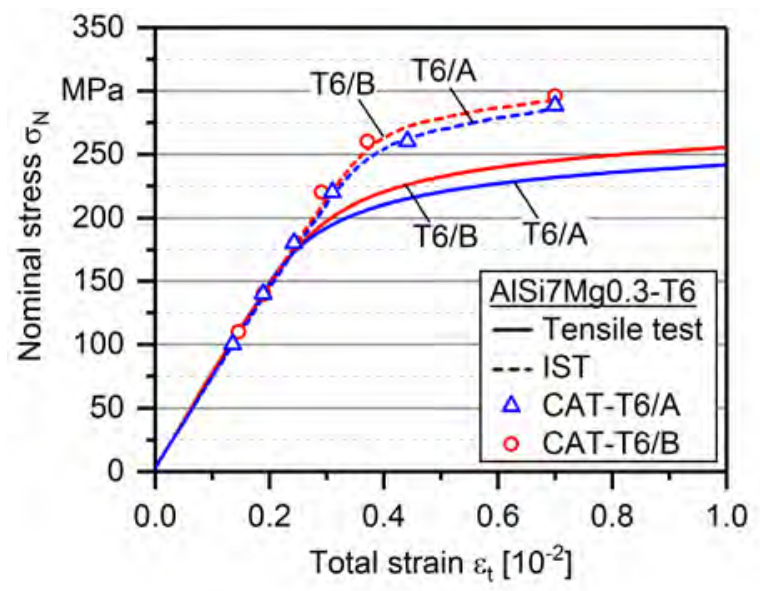

Fig. 8. Comparison of monotonic and cyclic stress-strain curves for batches T6/A and T6/B based on tensile tests and IST $\left(6^{\text {th }}\right.$ block for T6/A and $4^{\text {th }}$ block for T6/B) and validated by $\operatorname{CAT}\left(\sigma_{\mathrm{a}}\right.$ and $\varepsilon_{\mathrm{a}, \mathrm{t}}$ at $\left.\mathrm{N}_{\mathrm{i}} / 2\right)$.

The stress-strain behaviour of quasistatic tensile tests and IST was quantified by the following equations of Morrow:

$$
\begin{array}{ll}
\text { Tensile test: } & \sigma_{a 1 / 4}=K^{\cdot}\left(\varepsilon_{a, p 1 / 4}\right)^{n} \\
\text { IST : } & \sigma_{a}=K^{\prime} \cdot\left(\varepsilon_{a, p}\right)^{n^{\prime}}
\end{array}
$$

In Table 4, the monotonic and cyclic strain hardening exponents $n$ and $n$ ' and the monotonic and cyclic strength coefficients $K$ and $K^{\prime}$ as well as the cyclic yield strength $\sigma_{\mathrm{y} 0.02}$, are compared for batches T6/A and T6/B.

Table 4. Comparison of monotonic and cyclic stress-strain properties for both batches based on tensile tests and IST.

\begin{tabular}{|c|c|c|c|c|c|}
\hline Batch & $\begin{array}{c}\mathbf{n} \\
{[-]}\end{array}$ & $\begin{array}{c}\mathbf{K} \\
{[\mathrm{MPa}]}\end{array}$ & $\begin{array}{c}\mathbf{n}, \\
{[-]}\end{array}$ & $\begin{array}{c}\mathbf{K}, \\
{[\mathrm{MPa}]}\end{array}$ & $\begin{array}{c}\sigma_{\mathbf{y} 0.02} \\
{[\mathbf{M P a}]}\end{array}$ \\
\hline
\end{tabular}




\begin{tabular}{|c|c|c|c|c|c|}
\hline T6/A & 0.0824 & 368.9 & 0.0534 & 388.4 & 243.7 \\
\hline T6/B & 0.0758 & 371.6 & 0.0461 & 381.8 & 246.6 \\
\hline
\end{tabular}

\subsection{Fatigue behaviour}

The fatigue behaviour was determined by total strainand stress-controlled CAT from $10^{2}$ to $10^{7}$ cycles. The total strain-controlled CAT performed with an amplitude of $\varepsilon_{\mathrm{a}, \mathrm{t}}=0.7 \%\left(\mathrm{R}_{\varepsilon}=-1, \mathrm{f}=0.1 \mathrm{~Hz}\right)$ and stress-controlled CAT at stress amplitudes between 100 and $260 \mathrm{MPa}$ $(\mathrm{R}=-1, \mathrm{f}=65 \mathrm{~Hz})$. The crack initiation could be determined for each test and was used as failure criteria for strain- and stress-controlled CAT. Hereby, the crack initiation under strain control was determined by a stress drop of $1 \%$ related to steady state stress amplitude $\sigma_{\mathrm{a}^{*}}$ before failure: T6/A $\sigma_{\mathrm{a}^{*}}=293.0 \mathrm{MPa}, \quad \mathrm{T} 6 / \mathrm{B}$ $\sigma_{a^{*}}=296.7 \mathrm{MPa}$. For stress-controlled CAT, the crack initiation was determined in resonant testing system by a resonant frequency drop of $0.01 \%$ for specimens related to the steady state resonant frequency $\mathrm{f}^{*} \approx 65 \mathrm{~Hz}$.

In Fig. 9, the S-N diagrams are plotted for both batches. Hereby, for strain-controlled CAT the stress amplitude $\sigma_{\mathrm{a}}$ was determined at half of number of cycles to crack initiation $\mathrm{N}_{\mathrm{i}} / 2$. Moreover, the ultimate tensile strength determined by quasistatic tensile test is plotted in the S$\mathrm{N}$ diagram, using $\mathrm{N}_{\mathrm{i}}=0.25$.

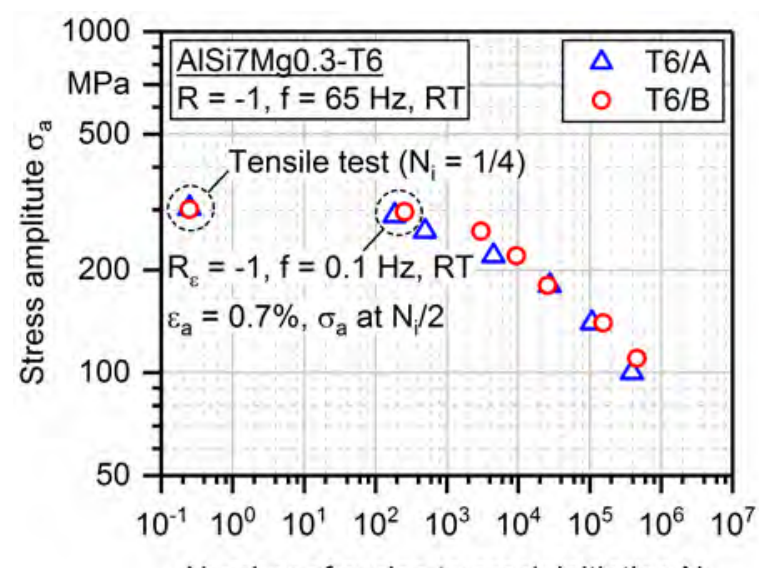

\section{Number of cycles to crack initiation $\mathrm{N}$}

Fig. 9. S-N diagram from $\mathrm{LCF}$ to $\mathrm{HCF}$ regime for batches T6/A and T6/B including strain-controlled CAT $\left(\varepsilon_{\mathrm{a}}=0.7 \%, \sigma_{\mathrm{a}}\right.$ at $\left.\mathrm{N}_{\mathrm{i}} / 2\right)$ and ultimate tensile strength $\left(\mathrm{N}_{\mathrm{i}}=0.25\right)$.

As batches T6/A and T6/B show significant differences in hardness, quasistatic and cyclic stress-strain curves, batch T6/A shows a decreased fatigue lifetime in the LCF regime, but only a slightly decreased lifetime in the HCF regime. Hereby, the most significant differences for both batches could be determined in the fatigue regime between $10^{2}$ and $10^{4}$ cycles to crack initiation. While the fatigue strength for each batch shows a linearly decrease in log-log diagram at higher lifetime $\mathrm{N}_{\mathrm{i}}>10^{4}$, the fatigue strength approximates to the ultimate tensile strength in the LCF regime.
Based on the monotonic and cyclic tests, the damage parameter $P_{S W T}$ related to Smith, Watson and Topper was determined by following equation

$$
P_{S W T}=\left(\sigma_{\max } \cdot \varepsilon_{a, t} \cdot E\right)^{0.5}
$$

containing maximum stress $\sigma_{\max }$, total strain amplitude $\varepsilon_{a, t}$ and Young's modulus $E$. The damage parameters $P_{S W T}$ for each test (tensile test, IST, CAT) and botch batches are plotted versus number of cycles to crack initiation in Fig. 10 as P-N diagram.

The P-N diagram underlines the results of S-N diagram, in which an influence of microstructure could be determined for LCF regime, but no significant changes in lifetime related to HCF regime. In contrast to S-N diagram, the correlation between damage parameter and lifetime can be described by a power law for each batch over the complete lifetime from tensile test to CAT in the $\mathrm{HCF}$ regime, as shown by a straight line in $\log (\mathrm{P})$ $\log (\mathrm{N})$ diagram.

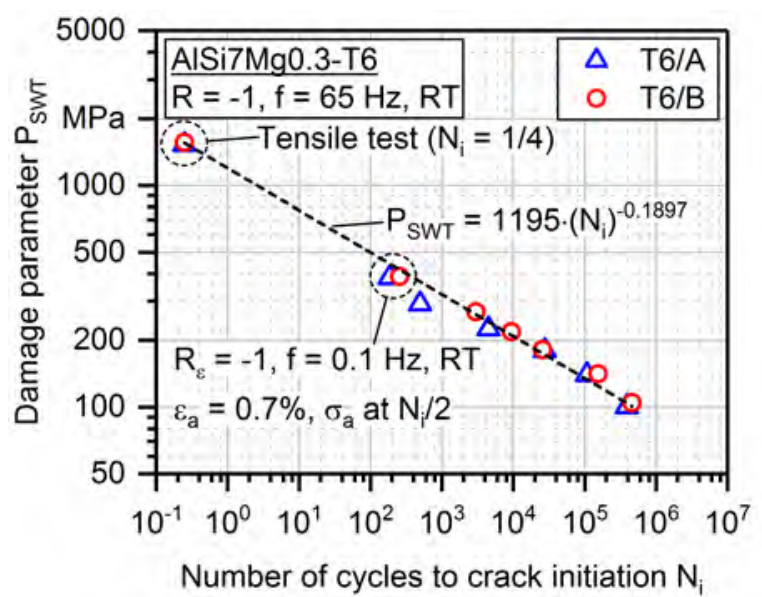

Fig. 10. P-N curves from LCF to HCF regime for batches T6/A and T6/B including strain-controlled CAT $\left(\varepsilon_{\mathrm{a}}=0.7 \%, \sigma_{\mathrm{a}}\right.$ at $\left.\mathrm{N}_{\mathrm{i}} / 2\right)$ and quasistatic tensile tests $\left(\mathrm{N}_{\mathrm{i}}=0.25\right)$.

\subsection{Fractographic investigations}

For batches T6/A and T6/B the fracture surfaces were analysed to determine the role of microstructural features like $\alpha$-Al solid solution hardness and interdendritic $\mathrm{Si}$ particles on the fatigue behaviour.

As the most significant differences could be determined in the LCF regime, the focus is set on the total straincontrolled CAT at an amplitude of $0.7 \%$. In Fig. 11, the fracture surface is shown for batch T6/A. The fatigue crack initiates at small remnant pores (Fig. 11a) and interacts with the dendritic and interdendritic microstructure during fatigue crack propagation phase. Hereby as exemplarily shown in Fig. 11b, a high amount of cracked Si particles or particles, respectively, in the interdendritic $\mathrm{Al}-\mathrm{Si}$ eutectic could be determined along the fatigue crack on the fracture surface. 

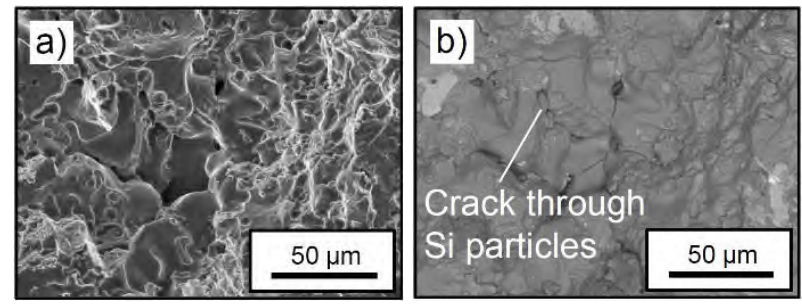

Fig. 11. Characteristic fracture surface in LCF regime for batch T6/A: a) Crack initiation at remnant porosity, b) cracking through Si particles.

In Fig. 12, the fracture surface of T6/B specimens in the LCF regime is shown. Hereby, the crack initiation also starts from remnant pores (Fig. 12a). In contrast to T6/A, the crack propagates between silicon particles and $\alpha-\mathrm{Al}$ solid solution, leading to a debonding of Si particles.

Further investigations were performed to understand the interaction of fatigue loading on the cyclic hardening and softening of the microstructure. Therefore, micro hardness mappings using a force of $0.09807 \mathrm{~N}$ (HV0.1) were carried out. Hereby, longitudinal cross sections of the specimen of the strain-controlled CAT $\left(\varepsilon_{a, t}=0.7 \%\right)$ were cut perpendicular to the crack surface including the clamped region in order to enable a direct comparison of loaded and unloaded regions as schematically shown in Fig. 13.
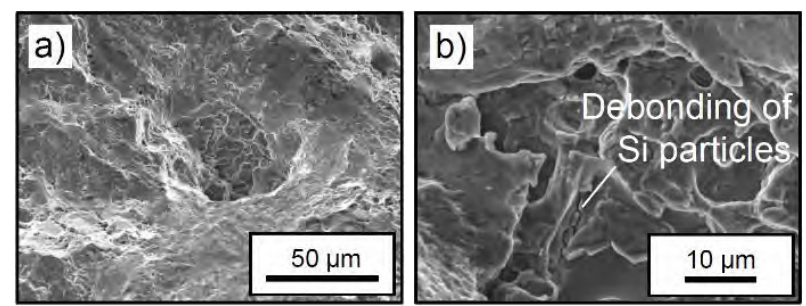

Fig. 12. Characteristic fracture surface in LCF regime for batch T6/B: a) Crack initiation at remnant porosity, b) debonding of Si particles within $\alpha$-Al solid solution.

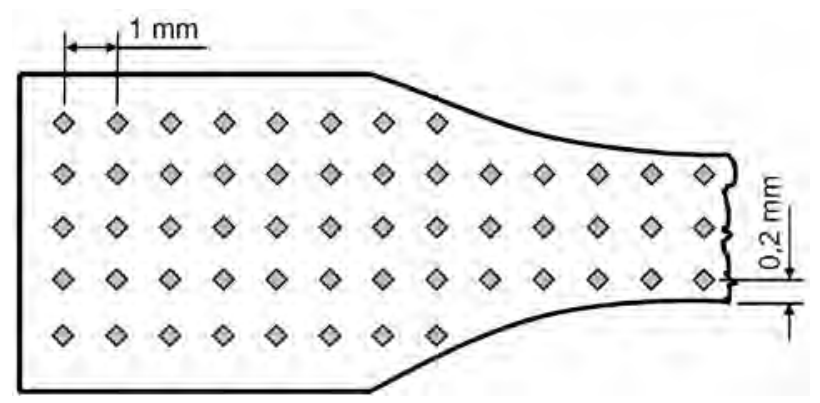

Fig. 13. Schematic illustration of micro hardness mappings on longitudinal cross sections for fractured CAT specimens.

In Fig. 14, the micro hardness mappings for the longitudinal cross sections are compared for batches T6/A (a) and T6/B (b). While the fatigue loading in the LCF regime leads to an increased hardness in loading region of specimen T6/B due to cyclic hardening as determined in Fig. 6, a decreased hardness in the loaded region compared to unloaded region could be determined for batch T6/A. (a)

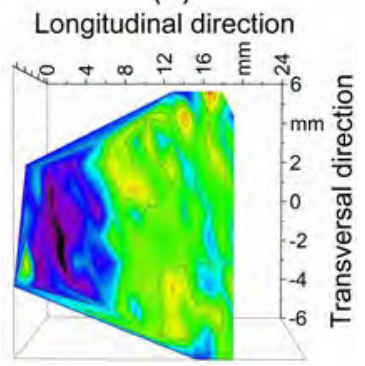

(b)

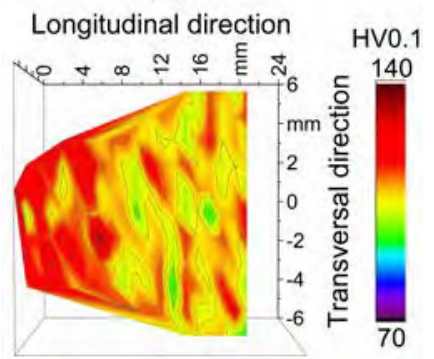

Fig. 14. Hardness mappings on fatigue loaded longitudinal cross sections of a) T6/A and b) T6/B.

For a better comparison of hardness distribution due to fatigue loading, the average micro hardness over longitudinal distance from fracture surface is plotted for both batches in Fig. 15. The initial hardness of each batch could be determined in the unloaded regions to around $95 \mathrm{HV} 0.1$ for batch T6/A and $108 \mathrm{HV} 0.1$ for batch T6/B. As already mentioned, the fatigue loading leads to an increased hardness of $131 \mathrm{HV} 0.1$ (closest to fracture surface) for batch T6/B. For batch T6/A, a decrease of hardness could be determined in the loaded region with a hardness minimum of $76 \mathrm{HV} 0.1$.

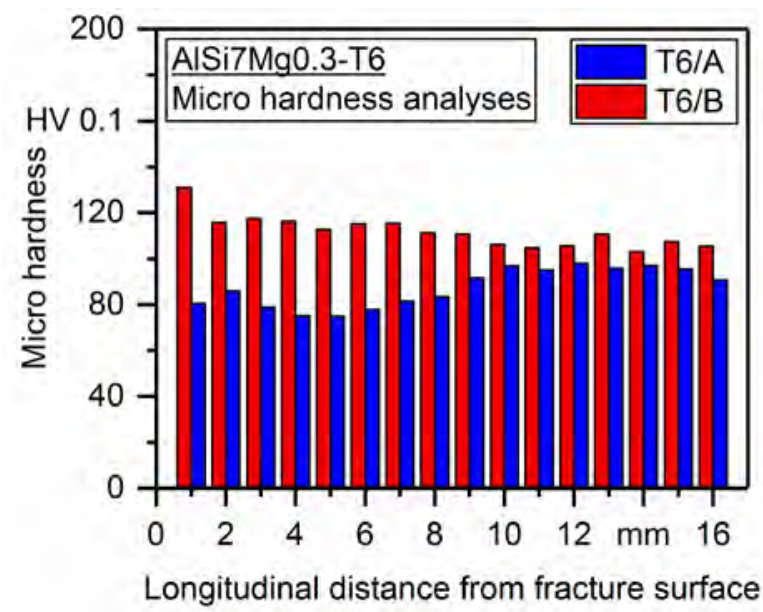

Fig. 15. Distribution of hardness related to distance from fracture surface due to fatigue loading for batch a) T6/A and b) T6/B

As the fracture surfaces in Fig. 11b showed a dominating cracking of $\mathrm{Si}$ particles in the interdendritic $\mathrm{Al}-\mathrm{Si}$ eutectic, it is assumed that this phenomenon can be attributed to the decreased hardness in T6/A. The reason for cracked $\mathrm{Si}$ particles in T6/A and debonded $\mathrm{Si}$ particles in $T 6 / \mathrm{B}$ is related to the coarsening of the 
eutectic Si particles in batch T6/B due to higher solution temperatures as already mentioned and shown in Table 2. The interaction of particles with dislocations dependent on the applied shear stress can be schematically described by Fig. 16 [15].

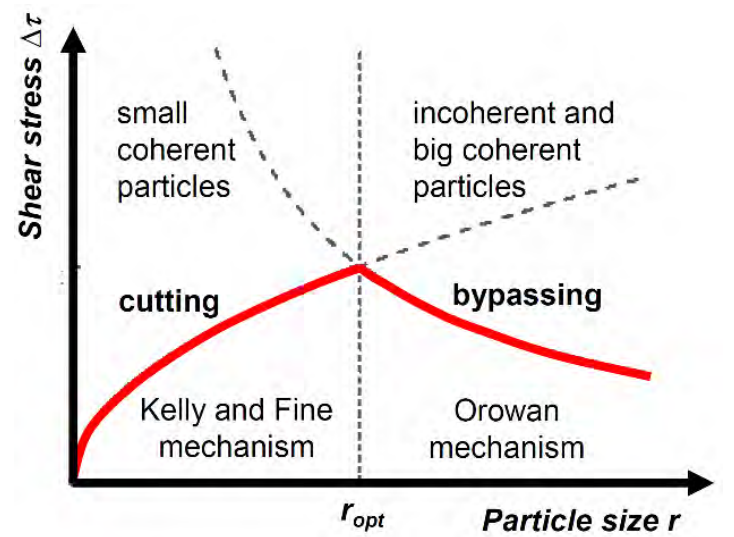

Fig. 16. Interaction of particle size $r$ and applied shear stress $\Delta \tau$ related to Kelly and Fine (cutting of dislocations) and Orowan mechanism (bypassing of dislocations) [15].

The dominating interaction mechanisms of particle size and applied stress (here: shear stress) can be explained by mechanisms by the Kelly and Fine (cutting) and Orowan (bypassing). In regions of dominating Kelly and Fine mechanism, the particles are cut by the applied stresses. This happens for small particles with a size smaller than $r_{\text {opt }}$ related to Fig. 16. For bigger particles, the Orowan mechanism dominates and the stress induced dislocations do not cut the particles, as bypassing the particles efforts less energy. The enveloped dislocation rings around the particles during bypassing are the reason for material hardening during monotonic and fatigue loading. As a dominating cutting of Si particles could be determined for batch T6/A and not for T6/B, it is assumed that the critical size of $\mathrm{Si}$ particles is within these two batches.

\section{Conclusions and outlook}

The effect of T6 heat treatment on the microstructure of aluminium cast alloy $\mathrm{AlSi} 7 \mathrm{Mg} 0.3$ was investigated by two different solution annealing conditions of $530^{\circ} \mathrm{C} /$ $1 \mathrm{hrs}$ for $\mathrm{T} 6 / \mathrm{A}$ and $545^{\circ} \mathrm{C} / 1 \mathrm{hrs}$ for $\mathrm{T} 6 / \mathrm{B}$, while using the same age hardening condition of $160^{\circ} \mathrm{C} / 5 \mathrm{hrs}$. Due to the difference in solution annealing temperature a significant effect on the morphology of the silicon particles in interdentritic Al-Si eutectic as well as the age hardening due to increased solubility of magnesium could be determined leading to an increased micro hardness of $\alpha$-Al solid solution by formation of $\mathrm{Mg}_{2} \mathrm{Si}$ precipitates. Therefore, T6/B features coarser Si particles compared to T6/A and an increased micro hardness of $\alpha$ Al solid solution.

The effect of coarsening of Si particles and hardness of $\alpha-\mathrm{Al}$ solid solution on the monotonic and cyclic mechanical behaviour was determined by quasistatic tensile tests, incremental step tests as well as strain- and stress-controlled constant amplitude test in the LCF and HCF regime. Hereby, an increased monotonic and cyclic yield strength could be determined for T6/B, which correlates to the increased micro hardness. Based on IST, it was possible to determine the cyclic stress-strain curve of botch batches, which underlines the planar slipping character of the age hardened aluminium cast alloy. The cyclic stress-strain curve was validated by comparison with strain- and stress-controlled CAT. While a significant increase in LCF lifetime could be determined for $\mathrm{T} 6 / \mathrm{A}$, which is attributed to the increased micro hardness and cyclic yield strength, both batches show a comparable lifetime in the $\mathrm{HCF}$ regime.

Fractographic investigations illustrate that there is a high amount of cracked Si particles within fracture surface of batch T6/A, whereby batch T6/B shows a debonding phenomenon instead of cracking of Si particles along the fatigue crack path. By a micro hardness mapping on longitudinal cross sections for fractured specimens of T6/A and T6/B in the LCF regime, a decreased micro hardness of loaded section compared to unloaded section could be determined for batch T6/A. Batch T6/B shows an increased micro hardness in the loaded section compared to unloaded section, which could be assumed due to cyclic hardening of the material as also could be determined in the IST investigations. It is assumed, that the decreased micro hardness for LCF specimens of T6/A is attributed to the cracking of Si particles.

To validate these results and assumptions TEM investigations should be performed to determine the influence of $\mathrm{Mg}_{2} \mathrm{Si}$ precipitates on the monotonic and cyclic stress-strain behaviour and on the decreased micro hardness of batch T6/A in the LCF regime. Moreover, further fractographic investigations are planned for the $\mathrm{HCF}$ regime to determine, if a cracking of $\mathrm{Si}$ particles can be detected as well.

Acknowledgements: The authors acknowledge the German Research Foundation (DFG) for the partial funding of the investigations presented within the framework of the research project WA 1672/15-1 and KR 1999/19-1 "Identification and modeling of damage mechanisms in Al-Si-Mg cast alloys during HCF and VHCF". Additionally, the authors express their special thanks to Ohm \& Haener Metallwerk GmbH for supplying A356 base alloy for casting.

\section{References}

1. J.Z. Yi, Y.X. Gao, P.D. Lee, T.C. Lindley, Metall. Mater. Trans. 37B (2006) 301-311

2. J. Tenkamp, A. Koch, S. Knorre, U. Krupp, W. Michels, F. Walther, Int. J. Fatigue 108 (2018) 25-34

3. Q.G. Wang, D. Apelian, D.A. Lados, J. Light Metals 1 (2001) 73-84

4. H.R. Ammar, A.M. Samuel, F.H. Samuel, Mater. Sci. Eng. 473A (2008) 65-75

5. J. Campbell, Metall. Mater. Trans. 37B (2006) 857863

6. Q.G. Wang, D. Apelian, D.A. Lados, J. Light Metals 1 (2001) 85-97 
7. B. Zhang, D. Poirier, W. Chen, Metall. Mater. Trans. 30A (1999) 2659-2666

8. M. Roy, Y. Nadot, C. Nadot-Martin, P. Bardin, D. Maijer, Int. J. Fatigue 33, 6 (2011) 823-832

9. L. Ceschini, A. Morri, G. Sambogna, J. Mater. Process Technol. 204 (2008) 231-238

10. C. Bowles, J. Schijve, Int. J. Fracture 9, 2 (1973) 171-179

11. M. Joyce, C. Styles, P. Reed, Int. J. Fatigue 25 (2003) 863-869

12. K. Shiozawa, Y. Thoda, S. Sun, Fatigue Fract. Eng. Mater. Struct. 20, 2 (1997) 237-247

13. C. Hollmann, TU Dresden (2004), PhD. Dissertation

14. H. Richard, B. Schramm, T. Zipsner, Springer (2017), ISBN 978-3-658-17779-9

15. F. Ostermann, Springer (2007), ISBN 978-3-54071196-4 